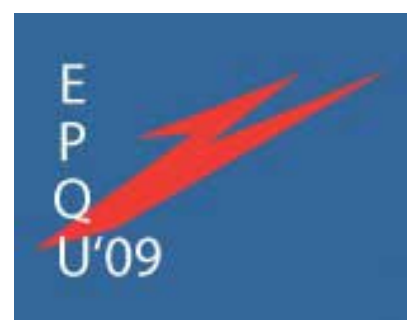

\title{
Estimation of Zero-Sequence Impedance of Undergrounds Cables for Single-Phase Fault Location in Distribution Systems with Electric Arc
}

\author{
S. Herraiz, J. Meléndez, V.A. Barrera \\ Institute of Informatics and Applications \\ University of Girona \\ Girona, Spain \\ sergio.herraiz@udg.edu
}

\author{
J. Sánchez, M. Castro \\ Endesa Distribución Eléctrica \\ Spain \\ jorge.sanchez@endesa.es
}

\begin{abstract}
This paper focus on the problem of locating singlephase faults in mixed distribution electric systems, with overhead lines and underground cables, using voltage and current measurements at the sending-end and sequence model of the network. Since calculating series impedance for underground cables is not as simple as in the case of overhead lines, the paper proposes a methodology to obtain an estimation of zero-sequence impedance of underground cables starting from previous singlefaults occurred in the system, in which an electric arc occurred at the fault location. For this reason, the signal is previously pretreated to eliminate its peaks voltage and the analysis can be done working with a signal as close as a sinus wave as possible.
\end{abstract}

Keywords-component; Power quality, voltage sags, underground cable, fault location, electric arc.

\section{INTRODUCTION}

Traditionally, fault location techniques have been developed for transmission electric lines due to the impact that faults would have on these kinds of lines. More recently, distribution lines have been taken more into account due to the improvement in the quality of power supply, derived from operating in a deregulated environment and the high competition between companies [1]. Due to the growing interest in power quality, digital recorders that capture power quality phenomena have become an important tool, so measurements of voltage and current before and during the fault are easily available and suitable to be used to estimate where the origin of the fault is located.

This work has been funded by the Ministry of Education and Science (Spanish acronym MEC) under the project DPI2006-09370 and ENDESA Distribución Eléctrica.
In literature, different methods for estimating the location of distribution line faults are described. One of these methods uses the fundamental frequency voltages and currents measured at the origin terminal of the line. It is known as impedancebased method, since it consists of calculating line impedance as seen from the line origin terminal and associating that value directly to a distance to the fault. R. Das describes in [2] the implementation of a fault location methodology based on impedances. For locating single-phase faults, the zero-sequence network is employed and information about the zero-sequence impedance of the line is needed.

Calculating series sequence impedance for underground cables is not as simple as calculating the series impedance of overhead lines [3]. An usual value for zero-sequence impedance of overhead lines is three times the positivesequence impedance [4] but the zero-sequence impedance of the cable is often difficult to be determined.

The paper proposes a methodology for estimating the zerosequence of the cable starting from previous faults occurred in the distribution system. Fault voltage and current measurements at the sending-end of the line and analysis of the fault (causes and location are known in that previous cases) are used to obtain a value for the zero-sequence impedance of underground cables, assuming that this data is known for overhead lines. Following the study presented in [5], the paper analyzes faults where an electric arc have occurred, with leads to register voltage signals with a higher harmonic distortion and to calculate a value of zero-sequence impedance that is not useful for different kind of faults, since it depends on the distortion of voltages.

The paper shows a simple and easy way to work with faults where an electric arc occurs, in order to obtain a single value of 
zero-sequence impedance of cables. This estimated value is used in new single-phase faults to locate their origin. The methodology is tested with real distribution system and fault data and results are discussed.

\section{FAULT LOCATION ALGORITHM}

Impedance-based fault location methods use the line parameters and the measurements of voltages and currents to obtain an estimation of the location of the fault. This estimation can be calculated by comparing the apparent reactance computed by using the faulted phase voltages and currents at one terminal and the modified reactance of the line between this terminal and the location of the fault [2]. The modified reactance between two nodes $\mathrm{M}$ and $\mathrm{R}$ is computed as

$$
\mathrm{X}_{\mathrm{MR}}^{\mathrm{m}}=\mathrm{X}_{1 \mathrm{MR}}+\frac{\mathrm{X}_{0 \mathrm{MR}}-\mathrm{X}_{1 \mathrm{MR}}}{3}
$$

where, $X_{0 \mathrm{mr}}$ and $\mathrm{X}_{\mathrm{lmr}}$ are the zero and positive sequence reactance between nodes $M$ and $R$, respectively.

If the modified reactance is less than the apparent reactance then the fault is located beyond node R. For a phase-to-ground fault, the apparent reactance is calculated as follows,

$$
\mathrm{X}_{\mathrm{m} 1}=\operatorname{Im}\left(\frac{\overline{\mathrm{V}}}{\overline{\mathrm{I}}}\right)
$$

where $\overline{\mathrm{V}}$ and $\overline{\mathrm{I}}$ are the voltage and current of the faulted phase at the monitored terminal.

\section{ESTIMATION OF ZERO-SEQUENCE OF CABLES}

Electrical parameters in underground cables are different from overhead lines. The shield of a cable use to be connected to ground in different points and the way the shields are connected and its connection resistance determines the path of zero-sequence impedance ¡Error! No se encuentra el origen de la referencia.. Therefore, zero-sequence impedance of cables is often difficult to be determined.

The methodology proposed in this paper is based on the assumption of knowing the location of previous faults occurred in the line. By analyzing those previous faults, for which the location of the fault is known, an estimation of a zero-sequence impedance for cables is calculated. This estimation would be used in case of new faults for calculating its location.

The methodology consist in the next steps:

- Apparent impedance is calculated from voltage and current registered at the substation during a phase-toground fault. Being the location of the fault known, the apparent impedance should be equal to the modified reactance from the substation to the fault.

- For overhead lines, zero-sequence impedance is considered to be equal to three times the positivesequence impedance [4].

- For cables, zero-sequence impedance is considered to be zero.

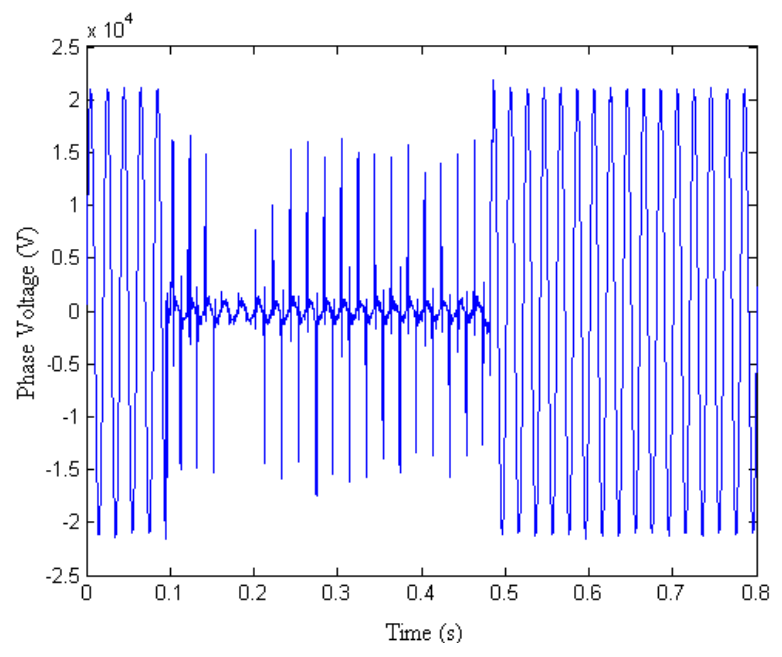

- Modified impedance from the substation to the fault is calculated, Eq. (1).

Figure 1. Voltage signal of a fault with electric arc (case 1).

- The difference between apparent impedance and modified impedance is considered that is due to zerosequence impedance of cable.

- An estimation of zero-sequence impedance of cable, $\Omega / \mathrm{km}$, is obtained by dividing the previous difference between the length of cable from the substation to the fault.

Several hypothesis have been taking into account in this methodology: a) all the difference between apparent and modified impedance are due to cable; b) the cable has homogeneous characteristics.

\section{FAULTS WITH ELECTRIC ARC}

Figure 1 shows the voltage of the faulted phase during a phase-to-ground fault. It can be noticed from the register that, during approximately a couple of cycles, the voltage is nearly a sinusoidal wave. Thus, if the methodology explained in Section III is applied, calculating the apparent reactance (2) during a cycle with the lowest harmonic distortion, a value of zerosequence impedance of the cable can be calculated.

Table I collects the values obtained for the four different registers that were recorded during that fault. In all of them, faulted phase voltage has at least one cycle with a waveform close to a sinusoidal wave. Thus, there is no need to treat the waveform (the signal is "non filtered"). From the results, it can be observed that the calculated zero-sequence is around 0.2 $\Omega / \mathrm{km}$.

TABLE I. NON-FILTERED CALCULATED ZER0-SEQUENCE IMPEDANCE (CASE 1)

\begin{tabular}{|c|c|c|}
\hline Register & Real Location $(\mathbf{k m})$ & Calculated $\mathbf{X}_{\mathbf{0}}(\mathbf{\Omega} / \mathbf{k m})$ \\
\hline $\mathrm{R} 1 \# 1$ & 1.69 & 0.2122 \\
\hline $\mathrm{R} 1 \# 2$ & 1.69 & 0.2321 \\
\hline $\mathrm{R} 1 \# 3$ & 1.69 & 0.1958 \\
\hline
\end{tabular}




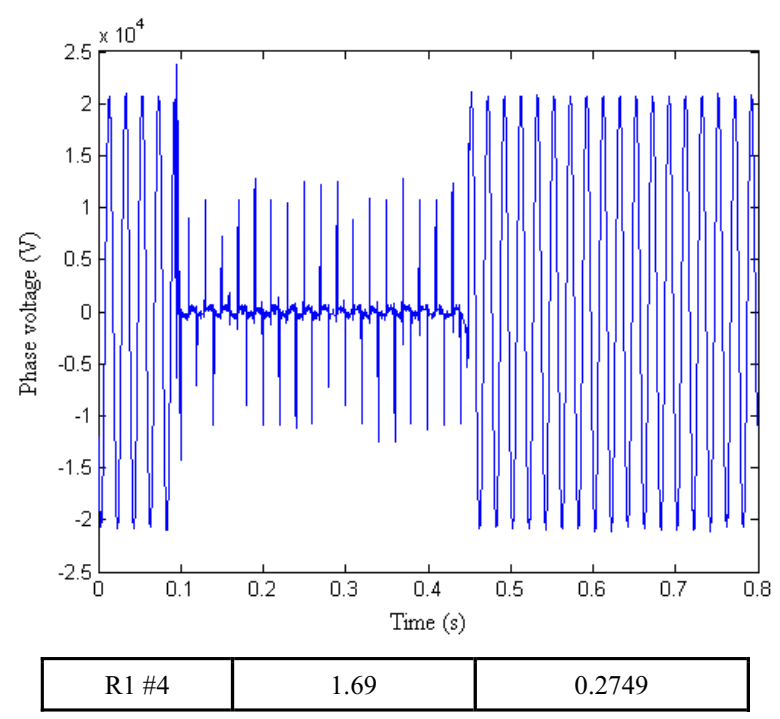

Figure 2. Voltage signal of a fault with electric arc (case 2).

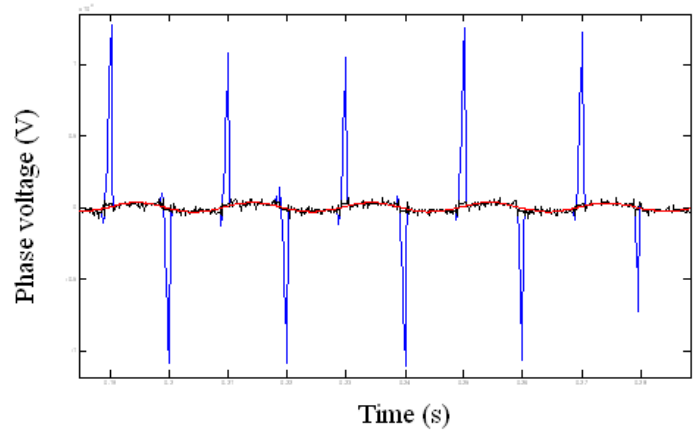

Figure 3. Filtered voltage signal (red curve) of a fault with electric arc (case 2).

Figure 2 shows the same information as Figure 1 for another phase-to-ground fault. In this case, considering all the registers recorded during the fault, the zero-sequence of the cable is also calculated as it was stated in Section III. The results are shown in Table II. In this case, the value has been obtained considering the cycle during the fault with the lowest harmonic distortion.

TABLE II. NON-FILTERED CALCULATED ZER0-SEQUENCE IMPEDANCE (CASE 2)

\begin{tabular}{|c|c|c|}
\hline Register & Real Location $(\mathbf{k m})$ & Calculated $\mathbf{X}_{\mathbf{0}}(\mathbf{\Omega} / \mathbf{k m})$ \\
\hline R2 \#1 & 0.38 & 4.57 \\
\hline R2 \#2 & 0.38 & 5.30 \\
\hline R2 \#3 & 0.38 & 0.79 \\
\hline R2 \#4 & 0.38 & 0.35 \\
\hline
\end{tabular}

Due to the fact that the signal is not sinusoidal (it can be observed than during the fault it exists a peak of voltage every half cycle), the calculated zero-sequence for the different registers during the fault has not a clear fixed value as the case presented before.

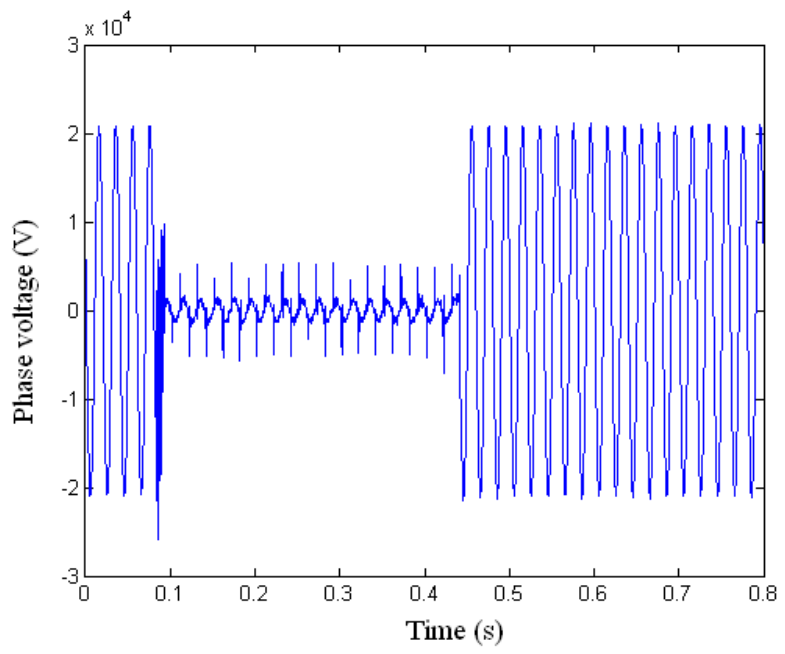

Figure 4. Voltage signal of a fault with electric arc (case 3).

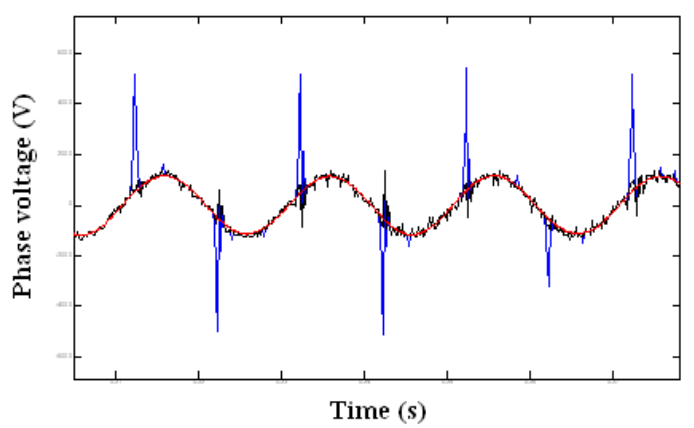

Figure 5. Filtered voltage signal (red line) of a fault with electric arc (case 3).

The same can be observed for fault presented in Figure 4 . However, in this case the estimated zero-sequence for the different registers obtained for this fault are in narrower range than the corresponding to the second case. This is due to the fact that the third fault is located farther relating to the measurement point (the depth of the voltage sag has a smaller value). The existence of one voltage peak each half cycle introduces a bigger variability of the zero-sequence impedances than the obtained in the first case.

TABLE III. NON-FILTERED CALCULATED ZER0-SEQUENCE IMPEDANCE (CASE 3)

\begin{tabular}{|c|c|c|}
\hline Register & Real Location $(\mathbf{k m})$ & Calculated $\mathbf{X}_{\mathbf{0}}(\boldsymbol{\Omega} / \mathbf{k m})$ \\
\hline R3 \#1 & 2.60 & 0.213 \\
\hline R3 \#2 & 2.60 & 0.3463 \\
\hline R3 \#3 & 2.60 & 0.194 \\
\hline R3 \#4 & 2.60 & 0.1934 \\
\hline
\end{tabular}

In order to try to reduce the variability of the estimated values of zero-sequence impedance, a filtered voltage wave was considered. This filtered wave is obtained to cutting off the peak voltages during the fault. Figures 3 and 5 show the filtered voltage waves (red lines) for case 2 and 3. 
Table 4 shows the obtained values for zero-sequence impedance starting from the filtered waves. It can be observed that the range of values is smaller for almost all the registers analyzed., around $0.2 \Omega / \mathrm{km}$ (the obtained value for the first case presented). Only two registers, corresponding to the second case, has a value significantly different from the others, R2 \#1 and R2 \#2. As it was commented before, these registers are recorded during a fault that occurs very close to the monitored point, so the values of voltages are close to zero and the calculated zero-sequence impedance could have a not good enough value.

TABLE IV. FILTERED CALCULATED ZER0-SEQUENCE IMPEDANCE (CASE 1,2 AND 3)

\begin{tabular}{|c|c|c|}
\hline Register & Real Location $(\mathbf{k m})$ & Calculated $\mathbf{X}_{\mathbf{0}}(\mathbf{\Omega} / \mathbf{k m})$ \\
\hline R2 \#1 & 0.38 & 0 \\
\hline R2 \#2 & 0.38 & 1.2547 \\
\hline R2 \#3 & 0.38 & 0.1519 \\
\hline R2 \#4 & 0.38 & 0.3612 \\
\hline R3 \#1 & 2.60 & 0.1829 \\
\hline R3 \#2 & 2.60 & 0.1723 \\
\hline R3 \#3 & 2.60 & 0.1689 \\
\hline R3 \#4 & 2.60 & 0.1615 \\
\hline R1 \#1 & 1.69 & 0.1736 \\
\hline R1 \#2 & 1.69 & 0.2244 \\
\hline R1 \#3 & 1.69 & 0.1106 \\
\hline R1 \#4 & 1.69 & 0.1966 \\
\hline
\end{tabular}

Finally, Table $\mathrm{V}$ shows the error in locating the fault considering an average value of $0.2 \Omega / \mathrm{km}$. In general, for all three cases there are registers with errors smaller than $10 \%$. In particular, for the first register in each case an error smaller than $10 \%$ is obtained, which can be considered as a good estimation of the location of the single line-to-ground fault.

\section{CONCLUSIONS}

A methodology for locating single-phase faults in mixed distribution electric systems is presented, considering that calculating series impedance for underground cables is not as simple as in the case of overhead lines. The paper proposes a methodology to obtain an estimation of zero-sequence impedance of underground cables starting from previous single-faults occurred in the system, in which an electric arc occurred at the fault location. The estimation is obtained by filtering the voltage peaks that can be observed during this type of faults, studying three well documented real cases, and showing that the value of zero-sequence impedance obtained would be suitable for locating the faults, since the error committed in the estimation is below $10 \%$. Future work will consider another different types of voltage waveforms.
TABLE V. CALCULATED FAULT LOCATION AND ERROR (CASE 1, 2 AND 3)

\begin{tabular}{|c|c|c|c|}
\hline Register & Real Location (km) & $\begin{array}{c}\text { Calculated Fault } \\
\text { Location (km) }\end{array}$ & $\begin{array}{c}\text { Error } \\
\mathbf{( \% )}\end{array}$ \\
\hline R2 \#1 & 0.38 & 0.42 & $1.16 \%$ \\
\hline & & 0.47 & $2.43 \%$ \\
\hline R2 \#2 & 0.38 & 0.59 & $5.56 \%$ \\
\hline R2 \#3 & 0.38 & 1.35 & $26.12 \%$ \\
\hline R2 \#4 & 0.38 & 0.00 & $-10.26 \%$ \\
\hline & & 0.42 & $1.16 \%$ \\
\hline R3 \#1 & 2.60 & 0.47 & $2.43 \%$ \\
\hline R3 \#2 & 2.60 & 0.27 & $-2.91 \%$ \\
\hline R3 \#3 & 2.60 & 2.32 & $-7.72 \%$ \\
\hline R3 \#4 & 2.60 & 2.32 & $-7.72 \%$ \\
\hline R1 \#1 & 1.69 & 2.32 & $-7.72 \%$ \\
\hline R1 \#2 & 1.69 & 2.32 & $-7.72 \%$ \\
\hline R1 \#3 & 1.69 & 1.35 & $-9.21 \%$ \\
\hline R1 \#4 & 1.69 & 1.70 & $0.35 \%$ \\
\hline & & 1.69 & $0 \%$ \\
\hline & & 0.47 & $-32.91 \%$ \\
\hline & & & $-9.21 \%$ \\
\hline
\end{tabular}

\section{REFERENCES}

[1] M.H.J. Bollen, Understanding Power Quality Problems, Voltage Sags and Interruptions, John Wiley \& Sons, New York, USA, 2000.

[2] R. Das. "Determining the Locations of Faults in Distribution Systems", Ph.D. dissertation, University of Saskatchewan Saskatoon, Canada, Spring 1998

[3] D.A. Tziouvaras, "Protection of High-Voltage AC Cables", 59th Annual Conference for Protective Relay Engineers, pp 48-61, April 2006.

[4] Cuaderno Técnico $n^{\circ}$ 18. Análisis de las redes trifásicas en régimen perturbado con la ayuda de las componentes simétricas. Schneider Electric. Marzo 2000.

[5] S. Herraiz, J. Meléndez, V.A. Barrera, J. Sánchez, M. Castro, "Estimation of the Zero-Sequence Impedance of Undergrounds Cables for Single-Phase Fault Location in Distribution Systems", SpanishPortuguese Conference on Electrical Engineering (accepted), July 2009.

[6] J. Amantegui, I. Zamora et alt., "Protección de líneas aéreas de transporte con tramos de cable". Undécimo Encuentro Regional Iberoamericano del CIGRÉ - XI ERIAC. Paraguay, 2005 